\title{
Plant Growth Promotion and Suppression of Damping Off in Tomato by Plant Growth Promoting Rhizobacterium Bacillus amyloliquifaciens
}

Canadian Journal of Agriculture and Crops

Vol. 5, No. 1, 59-68, 2020

e-ISSN: 2518-6655

Theck for updates $\begin{gathered}\text { check for } \\ \text { updates }\end{gathered}$

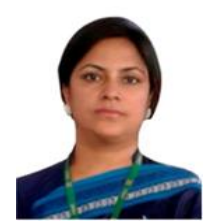

(\&) Corresponding Author)

\author{
Sultana F. ${ }^{10}$ \\ Islam M.R. ${ }^{2}$ \\ Sabbir M.A. ${ }^{s}$ \\ iD Hossain M.M. ${ }^{4}$
}

${ }^{1,3}$ College of Agricultural Sciences, International University of Business Agriculture and Technology, Dhaka, Bangladesh.

'Email:farjana1s@iubat.eduTel:+8801925871299

Email:sabbirahamedso1s@gmail.com Tel: +8801641380372

${ }_{2,4}^{2}$ Department of Plant Pathology, Bangabandhu Sheikh Mujibur Rahman Agricultural University, Gazipur, Bangladesh.

'Email: rabiulislam2949@gmail.com Tel:+8801551811891

'Email.hossainmm@bsmrau.edu.bdTel:+8801917049506

\section{ABSTRACT}

Plant growth promoting rhizobacterium (PGPR) is a kind of rhizosphere bacterium that increases plant growth and yield by intimately colonizing plant roots. This study was planned to examine the effect of a PGPR strain namely Bacillus amyloliquifaciens PPB10 on growth of tomato plants and suppression of damping off disease caused by Sclerotium rolfsii. In this study tomato seeds were treated with PPB10 and sown in sterilized soil. The PGPR isolate PPB10 significantly improved seed germination and seedling vigor of tomato plants compared to non-treated control. Three weeks after sowing, plants treated with the PGPR strain displayed significantly enhanced levels of growth in terms of length and yield of shoot and root biomass compared to non-treated control plants. Seed bacterization with the PGPR significantly increased total chlorophyll contents in the shoot. Moreover, the isolate significantly antagonized the mycelial growth of the pathogen Sclerotium rolfsii, while treating tomato seeds with the bacterium significantly suppressed damping off disease. The isolate was found to be an efficient colonizer of the tomato roots. Since the PGPR B. amyloliquifaciens PPB10 displayed traits beneficial to the plants, it has the potential to be utilized in the development of an effective seed treatment.

Keywords: PGPR, Seed germination, Vigor, Shoot growth, Root growth, Leaf number, Chlorophyll, Root colonization, Antagonist, Seedling mortality.

DOI: $10.20448 / 803.5 .1 .59 .68$

Citation | Sultana F.; Islam M.R.; Sabbir M.A.; Hossain M.M. (2020). Plant Growth Promotion and Suppression of Damping Off in Tomato by Plant Growth Promoting Rhizobacterium Bacillus amyloliquifaciens. Canadian Journal of Agriculture and Crops, 5(1): 59-68. Copyright: This work is licensed under a Creative Commons Attribution 3.0 License

Funding: The authors would like to acknowledge the Ministry of Science and Technology, Government of the People's Republic of Bangladesh for funding the project on "Biological control of broad spectrum plant diseases by plant growth promoting micro-organisms (PGPM) as an alternative approach to chemical control".

Competing Interests: The authors declare that they have no competing interests.

History: Received: 12 November 2019/ Revised: 16 December 2019/ Accepted: 20 January 2020/ Published: 6 March 2020 Publisher: Online Science Publishing 


\section{Highlights of this paper}

- $\quad$ Plant growth promoting rhizobacterium (PGPR) is a kind of rhizosphere bacterium that dynamically colonize the plant roots and improve plant growth and yield.

- The PGPR strain namely Bacillus amyloliquifaciens PPB10 significantly augmented growth of tomato plants and controlled damping off disease caused by Sclerotium rolfsii.

- Deployment of PGPR strain PPB10 for improvement of plant growth and suppression of diseases is considered as a key alternative to synthetic fertilizer and pesticides.

\section{INTRODUCTION}

Tomato (Lycopersicon esculentum) is one of the most common vegetables in Bangladesh and also a major crop in almost all countries in the world. It is rich in Vitamin A and Vitamin C, and serves as a potent source of antioxidant response compound such as lycopen which prevents carcinogenesis [1]. Tomato is principally well-known for its adaptive capacity to a wider range of soil and climatic conditions, and thus it is grown in almost all home gardens and fields in Bangladesh. Globally, tomato ranks third in respect of production next to potato and sweet potato [2] while in Bangladesh, it positions after potato and brinjal [3]. It is predominantly cultivated in winter season in Bangladesh as the prevailing temperature during this period of time is congenial for its optimum growth and yield. However, due to its palatability, demand of consumption is rising steadily throughout the year. Recent introduction of summer tomato has the potential to overcome the seasonality of the tomato production in Bangladesh. From farmer's point of view, tomato is known as profitable, less risky and high selling price recipient, compared with many field crops [4]. Because of these factors, farmers are bringing more land under tomato production, although the domestic production is still far from meeting the national demands. The imbalance in demand and production has led to excessive use of fertilizer and pesticides in the tomato field. Although, these agrochemicals directly benefit crop plants, they also impose negative effects on the environment and human health. Therefore, green strategies are needed to increase tomato production in Bangladesh. Utilization of beneficial microorganisms seems to be one of the prime substitutes of agrochemicals in agricultural field. Rhizosphere is a natural habitat of diverse groups of beneficial microbes. Plant growth promoting rhizobacterium (PGPR) is a heterogeneous group of rhizosphere bacteria that actively colonize plant roots and improve plant growth and yield. Among the PGPR, various strains of Bacillus have been effectively used in efforts to increase plant growth and control plant pathogens [5-9]. The commonly known mechanisms of plant growth enhancement by PGPR may include phytohormone production, nitrogen fixation, phosphate solubilization and harmful pathogen suppression. Presently, there is very limited evidence on the exploitation of PGPR in stimulating tomato growth in Bangladesh. Information on the efficacy of native PGPR population in stimulating tomato growth is necessary to develop eco-friendly formulation of the microbes for the field application. By keeping this in mind objectives were set to evaluate the indigenous PGPR isolate as a root colonizer for inducing growth traits and disease suppression capacity in tomato.

\section{MATERIALS AND METHODS}

\subsection{Location}

The Experiment was conducted at the Agriculture Field Laboratory of International University of Business Agriculture and Technology (IUBAT), Dhaka, Bangladesh and Microbiology Laboratory of Bangabandhu Sheikh Mujibur Rahman Agricultural University, Gazipur, Bangladesh.

\subsection{Origin of Seeds and Plant Growth Promoting Rhizobacterium}

The tomato plant Mintoo F1 cv. Year Round (Lal Teer Seed Company, Dhaka, Bangladesh) was used as host throughout the study. The PGPR strain Bacillus amyloliquifaciens PPB10 and the damping off pathogen Sclerotium 
rolfsii SR-1 were obtained from the microbial stock culture of Department of Plant Pathology, Bangabandhu Sheikh Mujibur Rahman Agricultural University (BSMRAU), Gazipur, Bangladesh. The rhizobacterial strain was previously isolated from the roots of cucumber (Cucumis sativus L. cv. Baromashi) plants. This strain had the ability to produce phytohormone IAA (Indole-3-Acetic Acid), fix N2 (nitrogen) and showed antagonistic activity against various pathogens [10].

\subsection{Culture and Preparation of Bacterial Inocula for Tomato Seed Treatment}

The bacterium was placed in a $300 \mathrm{ml}$ Erlenmeyer flask containing $100 \mathrm{ml}$ Yeast Peptone (YP) broth medium and cultured on a shaker at $120 \mathrm{rpm}$ (revolutions per minute) for $48 \mathrm{~h}$ at $28 \pm 2^{\circ} \mathrm{C}$. Bacterial cells were collected from the broth by centrifugation at $15000 \mathrm{rpm}$ for $1 \mathrm{~min}$ at $4^{\circ} \mathrm{C}$ followed by washing the bacterial pellet twice with sterile distilled water. The bacterial pellet was suspended in $0.5 \mathrm{ml}$ sterile distilled water, vortexed and used for seed treatment. Tomato seeds were surface sterilized in $5 \% \mathrm{NaOCl}$ for $1 \mathrm{~min}$, washed thrice in sterile distilled water and blotted dry. The dried seeds were then placed in bacterial suspension and the preparation was mixed thoroughly with frequent stirring for $5 \mathrm{~min}$. The treated seeds were spread out on a Petri plate and air dried overnight inside a clean bench at room temperature. The number of bacterium on the seed was approximately $10^{8}$ $\mathrm{CFU} /$ seed.

\subsection{Effect of Bacterial Seed Treatment on Germination and Vigor Index in Tomato}

With the aim of determining the impact of the PGPR treatment on seed germination and seedling vigor, 100 seeds were treated with the bacterium and incubated in ten 9-cm petri plates on two layers of sterile moistened filter paper. Seeds treated with water in place of bacterial suspensions were considered as a control treatment. Seeds were incubated at $28 \pm 2^{\circ} \mathrm{C}$ in a light incubator. Sufficient moisture was maintained for germination by adding $5 \mathrm{ml}$ distilled water to the petri plates every other day. If the radicles were half of the seed length, germination was estimated to have occurred. The germination percentage was recorded after 7 days. Plant length was measured from the root tip to the shoot tip. Vigor Index was estimated from the following formula:

Vigor Index $=\%$ Germination $\times$ total plant length

\subsection{Effect of Seed Treatment with Bacterium on Growth of Tomato Plant}

The rhizobacterial isolate was tested for its ability to stimulate growth in tomato plants. Surface-sterilized tomato seeds were treated with the rhizobacterial isolate as we described above. Surface-sterilized seeds treated with water were considered as control. Field soil containing $1.87 \%$ organic matter, $1.08 \%$ organic carbon, $0.27 \%$ nitrogen $(\mathrm{N})$, $0.09 \%$ phosphorus $(\mathrm{P})$ and $0.87 \%$ potassium $(\mathrm{K})$ with $\mathrm{pH} 6.38$ was used as potting medium. The soil was autoclaved twice at $24 \mathrm{~h}$ intervals at $121^{\circ} \mathrm{C}$ and $15 \mathrm{psi}$ (pounds per square inch) for 20 minutes. About $190 \mathrm{~g}$ of the sterilized soils were placed in each sterilized pot $(9.5 \mathrm{~cm} \times 7.0 \mathrm{~cm}$ size $)$. Treated tomato seeds were sown in each pot. Plants were cultivated in vinyl house and were watered on alternate days. After growing for three weeks, tomato plants were harvested and observation was made on fresh shoot weight, dry shoot weight, fresh root weight, dry root weight, shoot and root length, leaf number and leaf chlorophyll content. Number of leaves per plant was determined by counting the leaves from the base to the tip of the shoot.

\subsection{Determination of Photosynthetic Pigments}

Fresh leaves were harvested for extracting chlorophyll using the methods as described by Arnon [11]. Fresh leaf samples (0.5 g) was chopped and placed in a shaker with $80 \%$ acetone in dark until the leaves were entirely 
bleached. The aceton extract was centrifuged at 13,000 rpm for $10 \mathrm{~min}$, and the supernatant was collected to measure chlorophyll a (Chl a) and chlorophyll b (Chl b) at 663 and $645 \mathrm{~nm}$ absorbance, respectively, using a spectrophotometer. Cholorophyll a, chlorophyll b and total cholorophyll were calculated by using following formulas:

$$
\begin{gathered}
\text { Chlorophyll a }(\mu \mathrm{g} / \mathrm{ml})=12.7(\mathrm{~A} 663)-2.69(\mathrm{~A} 645) \\
\text { Chlorophyll b }(\mu \mathrm{g} / \mathrm{ml})=22.9(\mathrm{~A} 645)-4.68(\mathrm{~A} 663) \\
\text { Total chlorophyll }(\mu \mathrm{g} / \mathrm{ml})=20.2(\mathrm{~A} 645)+8.02(\mathrm{~A} 663)
\end{gathered}
$$

\subsection{In Vitro Screening of Bacterial Isolate for Antagonism}

Antagonistic activities of rhizobacterial strain against Sclerotium rolsii strain SR-1 was performed in dual culture assay. In this assay, both pathogen and bacterium were inoculated on the same potato dextrose agar (PDA) plate at $3 \mathrm{~cm}$ apart. The radial growth of the pathogen was measured after incubation at $25^{\circ} \mathrm{C}$ for 5 days. The percentage inhibition of pathogen radial growth was calculated by the following equation.

$$
\% \text { Inhibition of growth }=\frac{X-Y}{X} \times 100
$$

Where,

$\mathrm{X}=$ Mycelial growth of pathogen in the absence of antagonist.

$\mathrm{Y}=$ Mycelial growth of pathogen in the presence of antagonist.

\subsection{Inoculum Preparation of Sclerotium rolfsii}

Wheat grain $(100 \mathrm{~g})$ was taken in $100 \mathrm{ml}$ of distilled water in a $500 \mathrm{ml}$ Erlenmeyer flask and autoclaved at $121^{\circ} \mathrm{C}$ for $1 \mathrm{~h}$. The autoclaved wheat grains were inoculated with $10-15$ disks $(5 \mathrm{~mm})$ obtained from the actively growing margin of 5-day-old PDA cultures of $S$. rolfsii SR-1. After two weeks of incubation at $25^{\circ} \mathrm{C}$ in the dark, the fully colonized wheat grains were air-dried at laboratory temperature $\left(25 \pm 1^{\circ} \mathrm{C}\right)$. The dried wheat grain inocula were ground to fine particles $(1-2 \mathrm{~mm})$ and stored at $4{ }^{\circ} \mathrm{C}$ until use.

\subsection{Effect of Rhizobacterial Treatment on Damping Off of Tomato}

Field soil was autoclaved twice at 1 day interval at $121^{\circ} \mathrm{C}$ for $1 \mathrm{~h}$. Powdered wheat grain inoculum was mixed with the potting soil to a concentration of $1.0 \%(\mathrm{w} / \mathrm{w})$ before the tomato seeds were sown. Soil mixed with an equal amount of autoclaved wheat grain was used as a negative control. Plastic pots were filled with about $140 \mathrm{~g}$ of the potting medium and inoculum mixtures. Tomato seeds of PGPR and control treatment were prepared as above and were sown into the potting medium (10 seeds/pot). Each treatment consists of three replicates. Seedlings were grown in a growth room under the same conditions as described above. After 3 weeks of growth, number of survived seedlings were counted.

\subsection{Root Colonization}

Root colonization by the bacterium was determined following the protocol of Hossain, et al. [12]. Briefly, roots were collected from plants at one week, two weeks and three weeks after seed sowing. Roots were washed carefully with running tap water to eliminate adhering soil particles. The collected root samples were then rinsed thrice with sterile distilled water and finally blotted to dryness. Roots were segmented into top, middle and bottom regions. Each of root segments was weighed and homogenized in sterilized distilled water with mortar and pestle. Subsequently, appropriate dilutions were made and an aliquot of $100 \mu$ l suspension from each dilution was plated 
onto $\mathrm{KB}$ media. After $24 \mathrm{~h}$ of incubation at $28 \pm 2^{\circ} \mathrm{C}$, the number of bacterial colony was counted. Colony-forming units (CFU) per gram of root tissue was calculated for each sample by using the mean value of colony counts obtained from the triplicates.

\subsection{Statistical Analysis}

A completely randomized design was followed for each experiment, with three replications for each treatment. Each of the experiments were repeated at least twice and the data were shown from representative experiment with similar results. The data were statistically analyzed using SPSS (Version 17) and Microsoft Office Excel 2007. Significant difference between treatments were compared by using paired t test $(P=0.05)$.

\section{RESULTS AND DISCUSSION}

\subsection{Germination and Vigor Index Improvement in Tomato}

The bacterial treatment showed a significant effect on the germination rate and Vigor Index (VI) of tomato seedlings compared to the control. The PPB10 increased the germination rate of tomato seeds by $14.37 \%$ over the control, while the VI of seedlings was increased by $26.93 \%$ compared to the control Table 1 . These findings indicate that treatment with PPB10 can increase both the germination rate of seeds and vigor of seedlings in tomato.

\begin{tabular}{ccccc} 
& Table-1. Improvement of germination and vigor index of tomato by Bacillus amyloliquifaciens PPB10. & \% Increase in \\
\hline Treatment & \% Germination & $\begin{array}{c}\text { \% Increase in VI } \\
\text { germination over control }\end{array}$ & Vigor index (VI) & $\begin{array}{c}\text { \% Increr } \\
\text { over control }\end{array}$ \\
\hline Control & $75.56 \pm 2.21$ & - & $619.59 \pm 31.14$ & - \\
PPB 10 & $86.42 \pm 2.78^{*}$ & 14.37 & $786.42 \pm 38.45^{*}$ & 26.93 \\
\hline Note: *Indicates significant difference by t-test $(p<0.05)$. & &
\end{tabular}

\subsection{Plant Growth Promotion in Tomato Plants}

Plant growth enhancement has significantly been observed with the rhizobacterial treatment in tomato plants compared to non-inoculated control Figure 1. The mean shoot length of tomato plantlets ranged from $25.57 \mathrm{~cm}$ to $31.2 \mathrm{~cm}$. The maximum shoot length of $31.2 \mathrm{~cm}$ was found in PPB10 treated plants, while the lowest was in control-treated plants. The increase in shoot length by PPB10, was 22.02\% Table 2. Plants grown with the bacterial isolate showed longer primary roots and more secondary and lateral roots than the plants in control pots Figure 3. The maximum root length of $19.37 \mathrm{~cm}$ was found in treatment with isolate PPB10, which were $26.02 \%$ higher than control treatment Table 2. The PGPR pretreatment of tomato seed stimulated significantly higher fresh and dry shoot weight per plants as compared to untreated plants. The percent increase in shoot fresh and dry weight by PPB10 over control was $57.42 \%$ and $86.42 \%$, respectively. Tomato plants treated with the rhizobacterial strain had shown significantly higher fresh and dry root weight compared to those of untreated plants Table 2. The highest fresh root weight was obtained from PPB10 treated plants and the percent increment in root fresh weight by PPB10 over control was $80.16 \%$. Similarly, the highest and the lowest root dry weight were observed in PPB10 and control-treated plants, respectively. The leaf number was increased in PGPR-inoculated plants compared to those treated with control. The highest leaf number of 6.85 (7) plant ${ }^{-1}$ was observed in plants treated with PPB10 Table 2 which was $41.23 \%$ higher than control. These data indicate that the PPB10 is a PGPR that positively stimulates shoot and root growth in tomato plants. 
Table-2. Effect of seed treatment with Bacillus amyloliquifaciens PPB10 on shoot, root and leaf growth of tomato plants.

\begin{tabular}{|c|c|c|c|c|c|c|c|}
\hline Treatment & $\begin{array}{c}\text { Shoot } \\
\text { length }(\mathrm{cm})\end{array}$ & $\begin{array}{c}\text { Root } \\
\text { length }(\mathrm{cm})\end{array}$ & $\begin{array}{c}\text { Fresh shoot } \\
\text { weight (g) }\end{array}$ & $\begin{array}{l}\text { Dry shoot } \\
\text { weight (g) }\end{array}$ & $\begin{array}{l}\text { Fresh root } \\
\text { weight }(g)\end{array}$ & $\begin{array}{c}\text { Dry root } \\
\text { weight }(g)\end{array}$ & $\begin{array}{c}\text { Leaf number } \\
\text { /plant }\end{array}$ \\
\hline Control & $25.57 \pm 0.74$ & $15.37 \pm 0.56$ & $8.76 \pm 0.53$ & $0.81 \pm 0.04$ & $1.26 \pm 0.11$ & $0.16 \pm 0.01$ & $4.85 \pm 0.44$ \\
\hline PPB10 & $31.20 \pm .88^{*}$ & $19.37 \pm 0.58^{*}$ & $13.79 \pm 0.55^{*}$ & $1.51 \pm 0.09^{*}$ & $2.27 \pm 0.21$ & $0.26 \pm 0.01^{*}$ & $6.85 \pm 0.46^{*}$ \\
\hline $\begin{array}{l}\% \text { Increase } \\
\text { over control }\end{array}$ & 22.02 & 26.02 & 57.42 & 86.42 & 80.16 & 62.50 & 41.24 \\
\hline
\end{tabular}

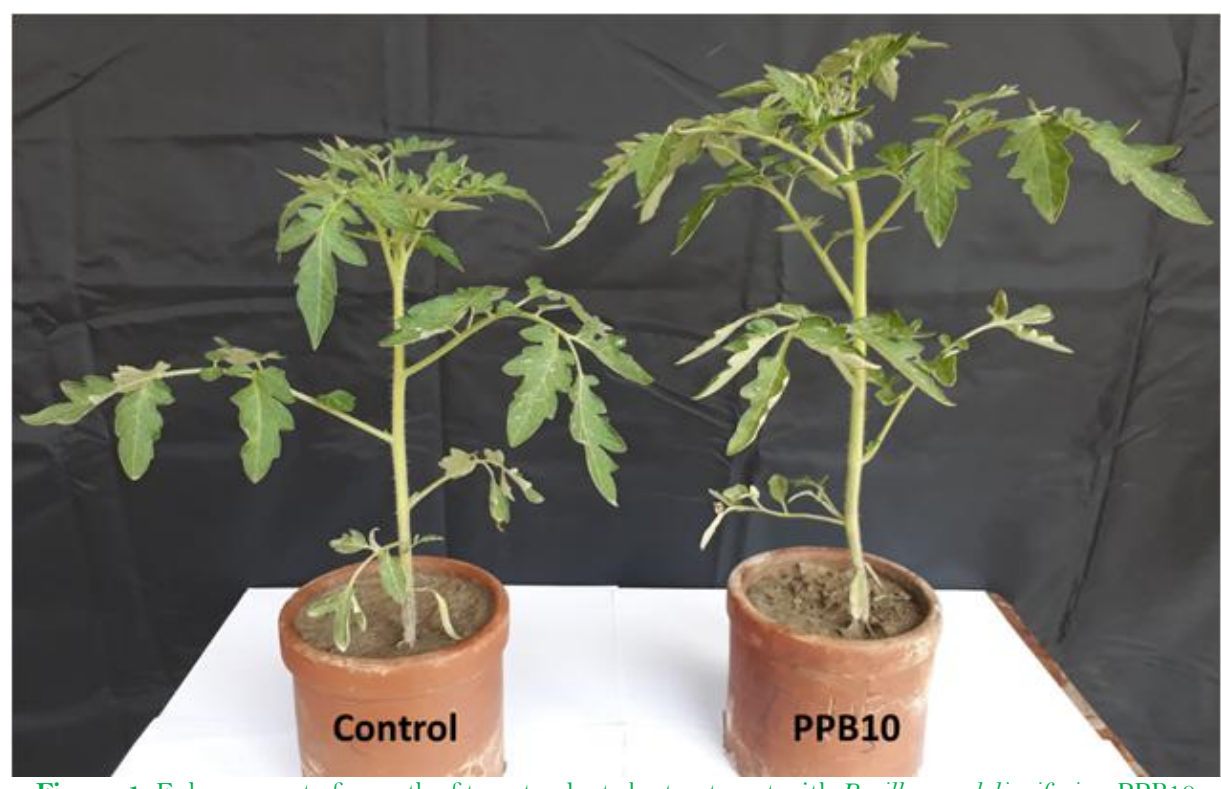

Figure-1. Enhancement of growth of tomato plants by treatment with Bacillus amyloliquifaciens PPB10.

\subsection{Improvement of Photosynthetic Compounds in Tomato Leaves}

It is clear from Table 3 that PPB10 significantly improved the photosynthetic pigments such as chlorophyll a and chlorophyll b in leaves of tomato plants when compared with the non-treated control plants. Such improvement was highly remarked in chlorophyll a contents. An increase of $32.20 \%$ leaf chlorophyll "a" content in plants grown in the presence of PPB10 was observed compared to the control. Similarly, the chlorophyll b and total chlrotophyll content were increased by $57.59 \%$ and $48.74 \%$, respectively in PPB10 treated plants compared to untreated control plants.

Table-3. Effect of seed treatment with Bacillus amyloliquifaciens PPB10 on photosynthetic pigment content in leaves of tomato plants.

\begin{tabular}{cccc}
\hline Treatment & \multicolumn{3}{c}{ Photosynthetic pigments $(\boldsymbol{\mu g} / \mathbf{g}$ fresh wt.) } \\
\cline { 2 - 5 } & Chlorophyll a & Chlorophyll b & Total Chlorophyll \\
Control & $15.56 \pm 0.50$ & $6.06 \pm 0.44$ & $20.23 \pm 0.53$ \\
PPB 10 & $20.57 \pm 0.51^{*}$ & $9.55 \pm 0.47^{*}$ & $30.09 \pm 0.78^{*}$ \\
\hline Note: *Indicates significant difference by t-test $(p<0.05)$. &
\end{tabular}

3.4. In Vitro Antagonism of Sclerotium rolfsii

The rhizobacterial isolate demonstrated substantial antagonistic activity towards $S$. rolfsii on PDA. In dual culture assay, mycelial growth of $S$. rolfsii was significantly inhibited by the presence of PPB10. The observed inhibition of mycelial growth of $S$. rolfsii was $62.90 \%$ by PPB10 compared to those in control plates Table 4 .

Table-4. Inhibition of mycelial growth of Sclerotium rolfsii and suppression of damping off in tomato by Bacillus amyloliquifaciens PPB10.

\begin{tabular}{ccccc}
\hline Treatment & $\begin{array}{c}\text { Diameter of mycelial } \\
\text { growth of } \boldsymbol{S} \text {. rolfsii }(\mathbf{c m})\end{array}$ & $\begin{array}{c}\text { \% Inhibition of mycelial } \\
\text { growth of } \boldsymbol{S} \text {. rolfsii }\end{array}$ & $\begin{array}{c}\text { \% Seedling } \\
\text { mortality }\end{array}$ & $\begin{array}{c}\text { \% } \\
\text { Protection }\end{array}$ \\
\hline Control & $43.83 \pm 0.74$ & - & $76.67 \pm 2.40$ \\
PPB10 & $16.26 \pm 0.45$ & $62.90 \pm 1.60$ & $43.29 \pm 1.17 *$ \\
\hline
\end{tabular}

Note: *Indicates significant difference by t-test $(p<0.05)$ 


\subsection{Suppression of Damping Off in Tomato}

Treatment with the PGPR strain PPB10 showed consistent suppression of damping off in the greenhouse experiments. The percent seedling mortality in control and PPB10-treated pots was recorded to be $76.67 \%$ and $43.29 \%$, respectively Table 4. Compared with the control, the average disease protection by PPB 10 was $43.54 \%$ against damping off in tomato.

\subsection{Root Colonization}

The root colonization ability of rhizobacterium is considered an essential factor to be effective plant growth promoters. In this study, the root colonization assays showed that the tested isolate vigourously colonized the roots of tomato plants. Nevertheless, the root population densities increased progressively with growth stages Figure 2 , where the lowest root population $\left(173 \times 10^{7} \mathrm{cfu}\right)$ was observed at the first week of growth and the largest root population $\left(322 \times 10^{7} \mathrm{cfu}\right)$ was found at the third week of growth.

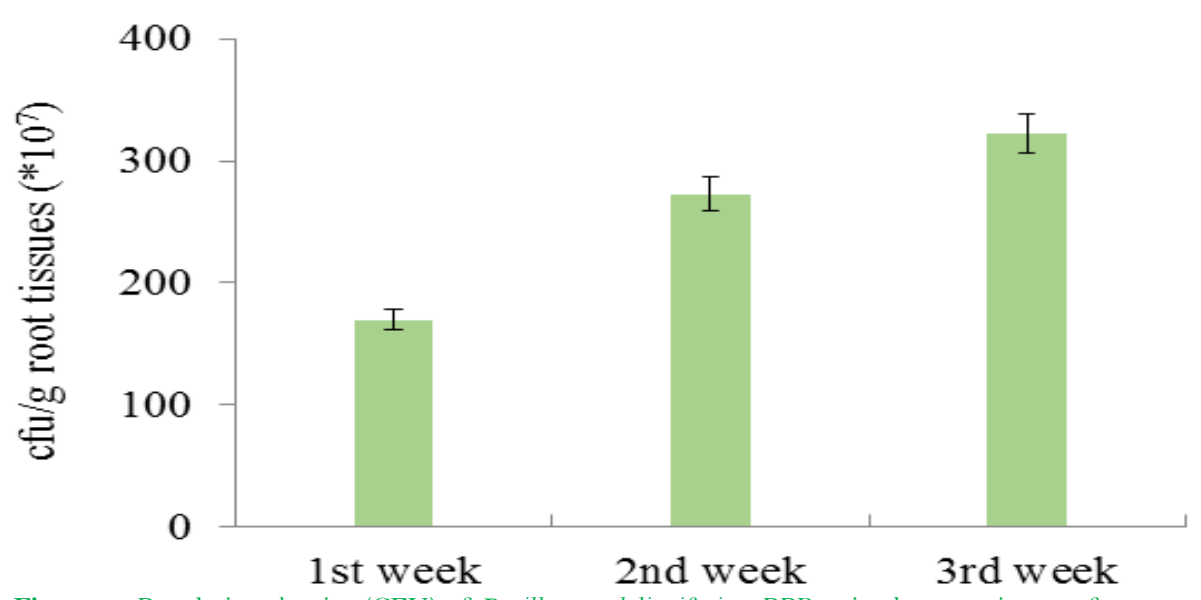

Figure-2. Population density (CFU) of Bacillus amyloliquifaciens PPB10 in the root tissues of tomato plants at different stages of growth.

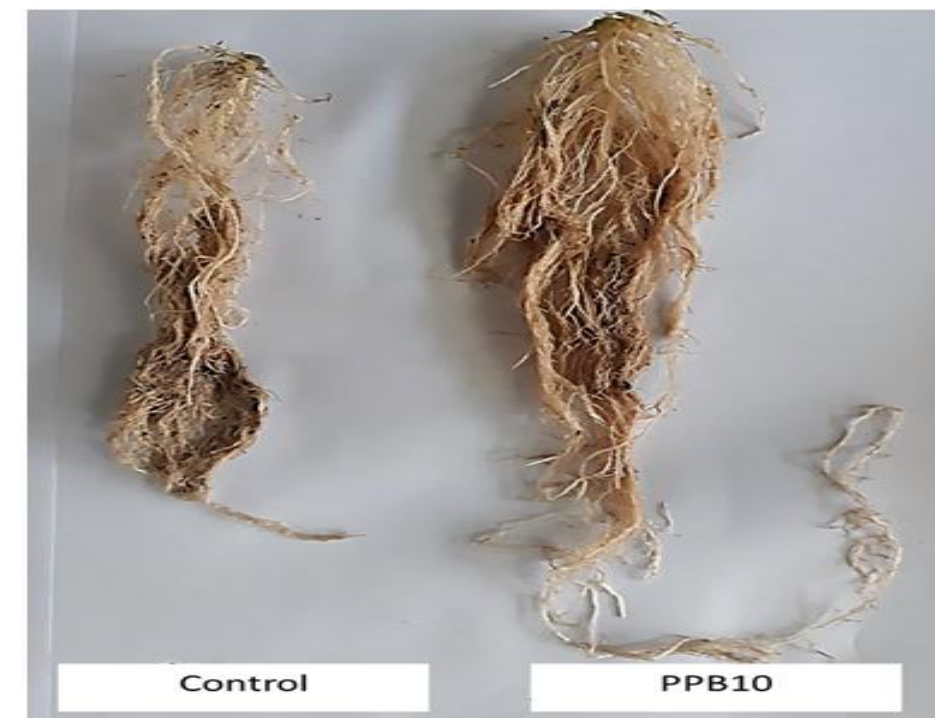

Figure-3. Plants grown with Bacillus amyloliquifaciens PPB10 showed longer primary roots and more secondary and lateral roots.

The rhizosphere is a narrow zone around plant roots, which habitats a large and dynamic microbial community [13]. Some of these rhizosphere bacteria have been the focus of many studies because of their beneficial interactions with plants. The PGPR, especially Bacillus spp., colonize roots of both monocot and dicot plants, and promote plant 
growth. We assessed phenotypic changes of tomato plantlets treated with a previously reported PGPR [10]. At 30 days after inoculation, plants treated with B. amyloliquifaciens PPB10 were taller and had healthier appearance than control plants. Treated plants had higher shoot biomass yield, leaf number and leaf chlorophyll content. Root architecture has also been altered after the PGPR inoculation. Plants treated with this PGPR had longer primary roots and possessed more secondary and lateral roots than control plants. Root weight was also increased after treatment with the PGPR, indicating that the PPB10 positively stimulate root biomass production. Based on these results, we conclude that the PGPR strain PPB10 promotes aerial and root growth of tomato plantlets.

Generally, microorganisms within the rhizomicrobiome can play an important role in promoting plant growth and providing better plant protection through several indirect or direct mechanisms [13]. In this study, the effects on plant growth and development associated with this PGPR strain may be mediated by Indole Acetic Acid (IAA) produced by it. Previous research discovered that the tested PGPR produced IAA and promoted cucumber plant growth [10]. In fact, the PGPR isolate PPB10 produced higher IAA than previously reported strains [14]. Production of IAA by the bacterium appears to be a vital mechanism of plant growth promotion because IAA plays an important role in root development and nutrient acquisition [15]. This commemorates with our findings that enhanced root growth was observed in the treated plants. In addition, improved nutrient uptake has been extensively documented in different plant species following inoculation with various PGPR. Acetylene reduction activity was shown by the PPB10, which is a commonly recognized proof for nitrogenase activity and $\mathrm{N}_{2}$-fixing ability [10]. Therefore, nitrogen fixation by the bacterium may seem to play an additional role in plant growth promotion of tomato plant. Transport of $\mathrm{N}$ from diazotrophic $\mathrm{N}$-fixing rhizobacteria to the roots of several nonleguminous crops has been confirmed [16]. This indicates a complex interplay of multiples mechanisms operated by the PGPR may have role in stimulating plant growth promotion in tomato plants.

In the present study, PGPR strain PPB10 applied as a seed treatment significantly suppressed damping off in tomato. This result indicates that the fungal antagonist B. amyloliquifaciens PPB10 is an effective biocontrol agent against tomato damping off pathogen $S$. rolfsii. Strains of $B$. amyloliquifaciens has been shown to be effective biocontrol agent against various pathogens in prior studies [10, 17]. The bacterium may produce one or more of antifungal compounds inhibitory to $S$. rolfsii. Competitive root colonization by PPB10 might also play an important role in the effectual control of soil-borne diseases. Colonization of plant roots by the bacterium appeared to be heterogeneous along the root system and its competitiveness concerning this process is an essential condition for plant growth promotion [18]. PGPR can interact with a wide range of plant species and establish mutualistic relationship with them. In this study, PPB10 was an efficient root colonizer, since the CFU counts for this strain were more than $10^{7} \mathrm{cfu} \mathrm{g}^{-1}$ root. Previously, this PGPR also colonized the roots of cucumber plants, indicating that this PGPR can colonize host of diverse taxonomic gorups. The lateral roots and root hairs are specially colonized by PGPR [19]. These regions have diverse roles for expressing their plant beneficial properties [20].

In this study, PGPR strain PPB10 improved seed germination and vigor of tomato seedlings. A positive effect on aerial and root biomass yields by the PGPR was observed. Seed bacterization with this PGPR also suppressed damping off disease caused by $S$. rofsii. These denote the potential of B. amyloliquifacience strain PPB10 for commercial use as biofertilizer and biocontrol agents in the tomato field.

\section{CONCLUSION}

The PGPR B. amyloliquifacience PPB10 significantly improved seed germination and seedling vigor of tomato plants compared to non-treated control. Seed bacterization with PPB10 significantly increased plant growth and leaf chlorophyll contents. Moreover, the root colonizing isolate extensively inhibited the radial growth of the 
pathogen Sclerotium rolfsii, while treating tomato seeds with the bacterium significantly suppressed damping off disease. Since this PGPR inoculant showed several traits beneficial to tomato plants, it may be utilized in the development of an effective seed treatment as a substitute to chemical fungicides.

\section{REFERENCES}

[1] R. D. Bhutani and G. Kallo, "Genetics of carotenoids and Iycopen in tomato (Lycopersicon esculentum Mill.)," Genetica Agraria, vol. 37, pp. 1-6, 1983.

[Q] M. E. Hossain, M. J. Alam, M. Hakim, A. Amanullah, and A. Ahsanullah, "An assessment of physicochemical properties of some tomato genotypes and varieties grown at Rangpur," Bangladesh Research Publications Journal, vol. 4, pp. 135243, 2010.

[3] BBS, Yearbook of agricultural statistics of Bangladesh. Dhaka: Planning Division, Ministry of Planning, Govt. of the People's Republic of Bangladesh, 2016.

[4] M. N. Islam, "Economic analysis of some selected crops under different treatment in saline soil at Charmajid, Noakhali," Annual Research Report, Agril. Economics Division, BARI, Gazipur2005.

[5] H. P. Bais, R. Fall, and J. M. Vivanco, "Biocontrol of Bacillus subtilis against infection of Arabidopsis roots by Pseudomonas syringae is facilitated by biofilm formation and surfactin production," Plant Physiology, vol. 134, pp. 307319, 2004a. Available at: https://doi.org/10.1104/pp.103.028712.

[6] C. Liu, X. Chen, T. Liu, B. Lian, Y. Gu, V. Caer, Y. Xue, and B. Wang, "Study of the antifungal activity of Acinetobacter baumannii LCHOO1 in vitro and identification of its antifungal components," Applied Microbiology and Biotechnology, vol. 76, pp. 459-466, 2007. Available at: https://doi.org/10.1007/s00253-007-1010-0.

[7] E. E. Idris, D. J. Iglesias, M. Talon, and R. Borriss, "Tryptophan-dependent production of indole-3-acetic acid (IAA) affects level of plant growth promotion by Bacillus amyloliquefaciens FZB42," Molecular Plant-Microbe Interactions, vol. 20, pp. 619-626, 2007. Available at: https://doi.org/10.1094/mpmi-20-6-0619.

[8] N. Messiha, A. Van Diepeningen, N. S. Farag, S. Abdallah, J. Janse, and A. Van Bruggen, "Stenotrophomonas maltophilia: A new potential biocontrol agent of Ralstonia solanacearum, causal agent of potato brown rot," European Journal of Plant Pathology, vol. 118, pp. 2 11-225, 2007. Available at: https://doi.org/10.1007/s10658-007-9136-6.

[9] X. Chen, A. Koumoutsi, R. Scholz, K. Schneider, J. Vater, R. Süssmuth, J. Piel, and R. Borriss, "Genome analysis of Bacillus amyloliquefaciens FZB42 reveals its potential for biocontrol of plant pathogens," Journal of Biotechnology, vol. 140, pp. 27-37, 2009. Available at: https://doi.org/10.1016/j.jbiotec.2008.10.011.

[10] S. Islam, A. M. Akanda, A. Prova, M. T. Islam, and M. M. Hossain, "Isolation and identification of plant growth promoting rhizobacteria from cucumber rhizosphere and their effect on plant growth promotion and disease suppression," Frontiers in Microbiology, vol. 6, pp. 1-12, 2016. Available at: https://doi.org/10.3389/fmicb.2015.01360.

[11] D. I. Arnon, "Copper enzymes in isolated chloroplast," Plant Physiol, vol. 24, pp. 1-15, 1949. Available at: https://doi.org/10.1104/pp.24.1.1.

[12] M. M. Hossain, F. Sultana, M. Kubota, and M. Hyakumachi, "Differential inducible defense mechanisms against bacterial speck pathogen in Arabidopsis thaliana by plant-growth-promoting-fungus Penicillium sp. GP16-2 and its cell free filtrate," Plant and Soil, vol. 304, pp. 227-239, 2008. Available at: https://doi.org/10.1007/s1 1104-008-9542-3.

[13] M. M. Hossain, F. Sultana, and S. Islam, Plant growth-promoting fungi (PGPF): Phytostimulation and induced systemic resistance. In: Singh D., Singh H., Prabha R. (Eds.), Plant-Microbe Interactions in Agro-Ecological Perspectives. Singapore: Springer, 2017.

[14] L. Ng, M. Sariah, O. Sariam, O. Radziah, and M. Zainal Abidin, "Rice seed bacterization for promoting germination and seedling growth under aerobic cultivation system," Australian Journal of Crop Science, vol. 6, pp. 170-175, 2012. 
[15] A. E. Carrillo, C. Y. Li, and Y. Bashan, "Increased acidification in the rhizosphere of cactus seedlings induced by Azospirillum brasilense," Naturwissenschaften, vol. 89, pp. 428-432, 2002. Available at: https://doi.org/10.1007/s00114-002-0347-6.

[16] J. P. Verma, J. Yadav, K. N. Tiwari, and A. Kumar, "Effect of indigenous Mesorhizobium spp. and plant growth promoting rhizobacteria on yields and nutrients uptake of chickpea (Cicer arietinum L.) under sustainable agriculture," Ecological Engineering, vol. 51, pp. 282-286, 2013. Available at: https://doi.org/10.1016/j.ecoleng.2012.12.022.

[17] M. T. Islam and M. M. Hossain, Biological control of peronosporomycete phytopathogen by bacterial antagonist. In: Maheshwari D. (Eds.), Bacteria in Bacteria in Agrobiology: Disease Management. Berlin, Heidelberg: Springer, 2013.

[18] B. Drogue, H. Doré, S. Borland, F. Wisniewski-Dyé, and C. Prigent-Combaret, "Which specificity in cooperation between phytostimulating rhizobacteria and plants?," Research in Microbiology, vol. 163, pp. 500-510, 2012. Available at: https://doi.org/10.1016/j.resmic.2012.08.006.

[19] E. Combes-Meynet, J. F. Pothier, Y. Moënne-Loccoz, and C. Prigent-Combaret, "The Pseudomonas secondary metabolite 2, 4-diacetylphloroglucinol is a signal inducing rhizoplane expression of Azospirillum genes involved in plant-growth promotion," Molecular Plant-Microbe Interactions, vol. 24, pp. 271-284, 2011. Available at: https://doi.org/10.1094/mpmi-07-10-0148.

[20] B. Lugtenberg and F. Kamilova, "Plant-growth-promoting rhizobacteria," Annual Review of Microbiology, vol. 63, pp. 541-556, 2009. Available at: https://doi.org/10.1146/annurev.micro.62.081307.162918.

Online Science Publishing is not responsible or answerable for any loss, damage or liability, etc. caused in relation to/arising out of the use of the content. Any queries should be directed to the corresponding author of the article. 